\title{
REMOVAL OF ANTIBIOTIC CIPROFLOXACIN HYDROCHLORIDE FROM WATER BY KANDIRA STONE: KINETIC MODELS AND THERMODYNAMIC
}

\section{GENÇ N.}

Received: 25/01/2015

Accepted: 02/04/2015

Available online: 24/06/2015
Department of Environmental Engineering

Faculty of Engineering, Kocaeli University

41380, Kocaeli, Turkey

*to whom all correspondence should be addressed: e-mail: ngenc@kocaeli.edu.tr

\section{ABSTRACT}

In this study, Kandira stone, extensively used as a cladding material for building stone has been examined for the removal of an antibiotic Ciprofloxacin hydrochloride (CIP) from its aqueous solution. Batch experiments were performed to investigate the adsorption kinetics, equilibrium and thermodynamics between the adsorbent surfaces and CIP. The sorption data follows Freundlich isotherm. A chemical adsorption was dominant. The adsorption behaviour of CIP onto Kandira stone followed the pseudo-second-order kinetic model, indicating that the adsorption process can be expressed with the chemisorption mechanism. The intraparticle diffusion process is a rate-controlling step. The adsorption thermodynamic parameters of the free energy change $\left(\Delta \mathrm{G}^{\circ}\right)$, the isosteric enthalpy change $\left(\Delta \mathrm{H}^{\circ}\right)$ and the entropy change $\left(\Delta \mathrm{S}^{\circ}\right)$ were calculated. The negative $\Delta \mathrm{H}^{\circ}$ values indicated that sorption of CIP was the exothermic process. The positive value of $\Delta \mathrm{G}^{\circ}$ indicates non-spontaneous nature of CIP adsorption.

Keywords Ciprofloxacin, adsorption, kinetic models, thermodynamic, Kandira stone

\section{Introduction}

Ciprofloxacin hydrochloride (CIP) is globally used an important fluoroquinolone antibiotics for treatment of both human and animal diseases. Due to the excret in unmetabolized form from the human and animal bodies, CIP was frequently detected in a variety of natural environments. CIP can exit the target organisms unaltered with up to $72 \%$ of the nonmetabolized form being excreted (Daughton and Ternes, 1999). Concentrations of CIP in wastewater effluents and surface water have been found at concentrations typically $<1 \mathrm{\mu g} \mathrm{I}^{-1}$ (Bhandari et al., 2008; Carmosini and Lee, 2009). Higher concentrations were reported in effluents from hospital (up to $150 \mu \mathrm{g} \mathrm{I}^{-1}$ ) and drug manufacturing plants (31 $\mathrm{mg} \mathrm{l}^{-1}$ ) (El-Shafey et al., 2012). Antibiotics fluoroquinolones become highly accumulated in sewage sludge (concentrations ranging from 1.4 to 2.42 $\mathrm{mg} / \mathrm{kg}$ of dry matter) (Golet et al., 2002).

Antibiotics can be removed effectively from the environment by adsorption on sludge, soils, and pure minerals (Wu et al., 2010). Low-cost adsorption method has attracted many researchers because of not requires complicated regeneration process (Kumar, 2014). Natural adsorbents are evaluated as an appropriate adsorbents due to its low cost and high removal efficiency.

Genç N. (2015), Removal of antibiotic Ciprofloxacin Hydrochloride from water by Kandira stone: Kinetic models and thermodynamic, Global NEST Journal, 17(3), 498-507. 
In the literature, several studies related to the adsorption of CIP to natural materials or components of natural materials have been published (activated carbon (Carabineiro et al., 2012); activated charcoal and talc (Ibezim et al., 1999); montmorillonite (Wu et al., 2010; Wu et al., 2012); soil (Carrasquillo et al., 2008; Vasudevan et al., 2009; Conkle et al., 2010); 2:1 dioctahedral clay minerals (Wang et al., 2011); kaolinite (Li et al., 2011); modified coal fly ash (Zhang et al., 2011); aerobically digested biosolid (Wu et al., 2009); sawdust (Bajpai et al., 2012); date palm leaflets (El-Shafey et al., 2012); birnessite, a layered manganese oxide (Jiang et al., 2013); $\left(\mathrm{Fe}_{3} \mathrm{O}_{4} / \mathrm{C}\right)$ a new magnetic mesoporous carbon composite (Shi et al., 2013); Chitosan-Zn (II), Chitosan-Fe (III), Chitosan-Fe(II) microparticles (Reynaud et al., 2011); aluminum and hydrous oxides (Gu and Karthikeyan, 2005); nano-sized magnetite (Rakshit et al., 2013).

The objective of this research is to investigate the capability of Kandira stone for the adsorption of CIP from aqueous solution. On the basis of batch adsorption experiments, kinetic models to predict the CIP removal efficiency of a low cost and natural adsorbent used is applied. Thermodynamic studies were also performed in order to explain the adsorption mechanism.

\section{Materials and Methods}

\subsection{Materials}

Kandira stone was used as adsorbent. Kandira stone, extensively used as a cladding material for building stone in northwest Turkey, consists of approximately $91 \%$ calcium carbonate and $9 \%$ clay minerals (Arman et al., 2007). Kandira stone was dried at air, passed through a $0.1 \mathrm{~mm}$ sieve to ensure the material uniformity.

CIP with purity higher than $99 \%$ was obtained from SANOVEL. This commercially available product contains no more than $0.2 \%$ by weight of the by-product contaminant fluoroquinolonic acid. CIP used in the experiments is the commercial product, with a molecular weight of 367.80 . The solubility of $\mathrm{CIP}$ is $\mathrm{pH}$ dependent, ranging from $6.19 \mathrm{~g} \mathrm{l}^{-1}$ at $\mathrm{pH} 5$ to $0.15 \mathrm{~g} \mathrm{l}^{-1}$ at $\mathrm{pH} 7$ at $37^{\circ} \mathrm{C}$ (Wu et al., 2010).

\subsection{Batch CIP Adsorption Experiments}

Batch adsorption experiments were conducted by CIP solution at concentration of $30 \mathrm{mg} \mathrm{I}^{-1}$. For a kinetic study, $0.6 \mathrm{~g}$ of Kandira stone was put into $50 \mathrm{~mL}$ of CIP solution. The initial $\mathrm{pH}$ values of the CIP solutions were not adjusted. The adsorption was carried out in the flask containing both Kandira stone and CIP solution at 20 ${ }^{\circ} \mathrm{C}$ and constant agitation (125 rpm). The concentrations of CIP in solution were analyzed with 5 - 60 min time intervals after the solids were separated by filtration.

For the isotherm study, Kandira stone and CIP solution at initial concentrations ranging from 3 to $30 \mathrm{mg} \mathrm{l}^{-1}$ were combined and mixed on a shaker at $125 \mathrm{rpm}, 20^{\circ} \mathrm{C}$ and initial $\mathrm{pH}$ for $30 \mathrm{~min}$. For the thermodynamic analysis, Kandira stone and CIP solution at initial concentration of 10, 20,30, $40 \mathrm{mg} \mathrm{l}^{-1}$ were combined and mixed at $20,30,40,50{ }^{\circ} \mathrm{C}$ at $125 \mathrm{rpm}$ for $30 \mathrm{~min}$ under initial $\mathrm{pH}$ condition. After mixing, samples were analyzed for equilibrium CIP concentration.

\subsection{Analysis}

The concentrations of CIP in the filtered supernatant were measured by means of the UV spectrometer (HachLange DR 5000). The concentration of CIP was analyzed at the maximum wavelength. The calibration curve was established with 17 standards between 0 and $50 \mathrm{mg} \mathrm{l}^{-1}$ with the coefficient of determination $\left(R^{2}=0.9992\right)$. The amount of CIP adsorbed at equilibrium was calculated according to Eq (1):

$$
\mathrm{q}_{\mathrm{e}}=\frac{\left(\mathrm{C}_{\mathrm{o}}-\mathrm{C}_{\mathrm{e}}\right) \mathrm{V}}{\mathrm{m}}
$$


where $\mathrm{q}_{\mathrm{e}}$ and $\mathrm{C}_{\mathrm{e}}$ are the amount of CIP was adsorbed per unit weight of the adsorbent $\left(\mathrm{mg} \mathrm{g}^{-1}\right)$ and the equilibrium concentration of CIP in solution $\left(\mathrm{mg} \mathrm{l}^{-1}\right)$ at equilibrium, respectively; $C_{0}$ is the initial concentration of CIP ( $\left.\mathrm{mg} \mathrm{l}^{-1}\right)$; $\mathrm{V}$ and $\mathrm{m}$ are the volume of CIP solution (I) and the mass of adsorbent used ( $\mathrm{g}$ ), respectively.

\section{Results and Discussion}

\subsection{Effect of adsorbent dosage}

Effect of adsorbent dose on removal of CIP investigated with adsorbent dose in the range of 2-24 $\mathrm{g} \mathrm{I}^{-1}$ at initial $\mathrm{pH}$ and CIP concentration of $30 \mathrm{mg} \mathrm{l}^{-1}$ (Fig. 1a). From Fig., it is obvious that, the amound of CIP adsorbed increased from around $18.1 \%$ to $68.5 \%$ when Kandira stone was increased from 2 to $12 \mathrm{~g} \mathrm{l}^{-1} .12 \mathrm{~g} \mathrm{l}^{-1}$ was selected as optimum dose. The removal of CIP increases sharply with increase in adsorbent dose due to the availability of more binding sites on adsorbent surface. After that, removal becomes in less significant rate. Percent removal increased to $77.4 \%$ up to dose of $24 \mathrm{~g} \mathrm{l}^{-1}$. It may be due to overlapping or aggregation of adsorption sites resulting in a decrease in total adsorbent surface area.

\subsection{Effect of contact time on the removal of CIP}

The equilibrium time is the most important design parameters in an economical wastewater treatment system. The adsorption capacity of Kandira stone was determined by varying the contact time in the range of 5-60 min (Fig. 1b). Optimum contact time is the amount of time required for maximum adsorption at minimum contact time. It is shown in Fig.1 that there was a rapid uptake within the first 30 min. The initial adsorption rate is rapid and gradually decrease with raising the time and reach equilibrium at about $30 \mathrm{~min}$ of contact time. Therefore, 30 min of contact time was chosen as the optimum contact time for Kandira stone. The amounts of CIP adsorbed increased from $48.1 \%$ to $63.9 \%$ when contact time increased from 5 min to $30 \mathrm{~min}$. Percent removal increased to $79.8 \%$ up to $60 \mathrm{~min}$.

\subsection{The effect of $\mathrm{pH}$ on the removal of CIP}

For investigating the $\mathrm{pH}$ dependence of CIP sorption, $30 \mathrm{mg} \mathrm{l}^{-1} \mathrm{CIP}$ solution was shaken with $12 \mathrm{~g} \mathrm{I}^{-1}$ Kandira stone and equilibrated for $30 \mathrm{~min}$ at $\mathrm{pH}$ values ranging from 1.0 to 12 . Comparison of removal efficiency at different values of $\mathrm{pH}$ shows that adsorbed CIP percentage is decreased by inceasing of $\mathrm{pH}$ (Fig.1c). The pKa values for CIP are 6.1 (for the carboxylic acid group) and 8.7 (for the amine group on the piperazine moiety). The cationic form due to protonation of the amine group in the piperazine moiety predominates when solution $\mathrm{pH}$ is below 6.1. $\mathrm{CIP}$ is the zwitterionic form of CIP dominates at $\mathrm{pH}$ 6.1-8.7. As the solution $\mathrm{pH}$ is above 8.7, the anionic form due to loss of a proton from the carboxylic group prevails (Wu et al., 2010). At $\mathrm{pH}<6.0$, removal of CIP increased because of the electrostatic attraction improved due to the opposite charge between CIP and Kandira stone. As can be seen, the removal percentage significantly decreased at higher $\mathrm{pH}$ values. This behavior may be attributed to the zwitterionic properties of CIP. In acidic solutions, high ionic interactions ocur between the cationic $\mathrm{CIP}^{+}$and adsorbents' surface. Because of these interactions, high removal of CIP is accomplished.

\subsection{Adsorption isotherms}

Equilibrium data, also known as adsorption isotherms, describe how the adsorbate' surface interaction between adsorbed molecules and give a comprehensive understanding of the nature of interaction (Moradi et al., 2013). In this study, several isotherm equations are applied.

\subsubsection{Langmuir isotherm}

Langmuir isotherm models the single coating layer on adsorption surface. Moreover, the adsorbent surface is homogeneous so, adsorption energy is constant over all sites. Langmuir isotherm can be defined as: 


$$
\frac{\mathrm{C}_{\mathrm{e}}}{\mathrm{q}_{\mathrm{e}}}=\frac{1}{\mathrm{kV} \mathrm{V}_{\mathrm{m}}}+\frac{\mathrm{C}_{\mathrm{e}}}{\mathrm{V}_{\mathrm{m}}}
$$

where $V_{m}$ is the monolayer capacity, $k$ is the equilibrium constant. These constants can be determined from the intercept and the slope of the linear plot of experimental data of $\mathrm{Ce} / \mathrm{qe} \mathrm{vs}$. Ce. The linear form of Langmuir equation for CIP adsorption on Kandira stone is given by the following expression (correlation coefficient, $\left.R^{2}=0.6311\right)$ :

$$
\frac{C_{e}}{q_{e}}=117.85-8.2534 C_{e}
$$

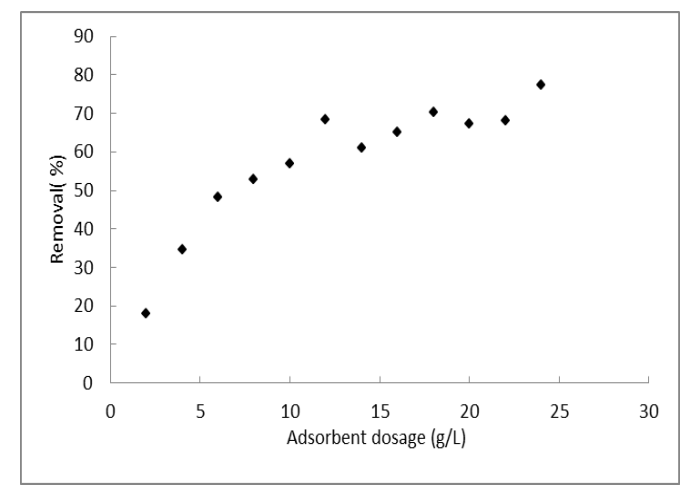

(a)

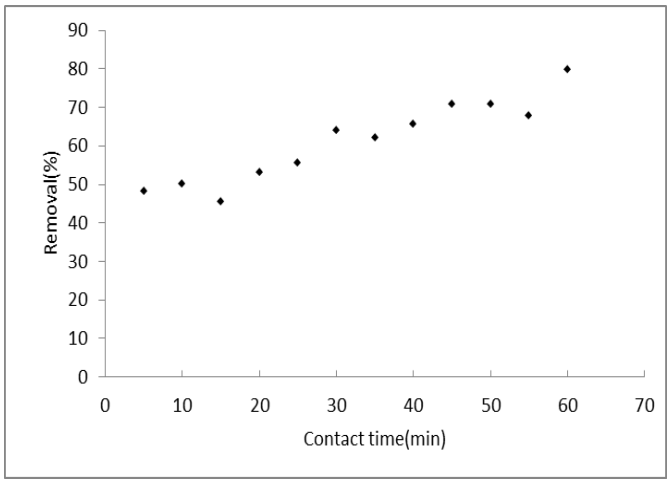

(b)

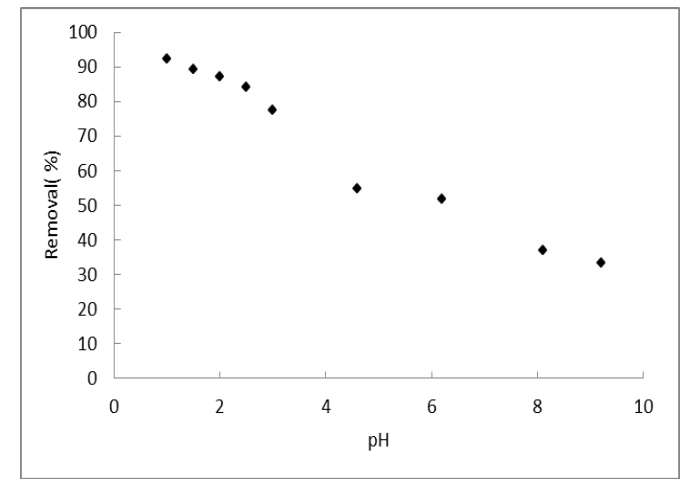

(c)

Figure 1. Effect of adsorbent dose (a), contact time (b), and pH (c) on the adsorption of CIP 


\subsubsection{Freundlich isotherm}

Freundlich isotherm is used for modelling the adsorption on heterogeneous surfaces. The linear form of Freundlich isotherm is written as the following equation:

$$
\log q_{e}=\log K_{f}+\frac{1}{n} \log C_{e}
$$

where $K_{f}$ is taken as a relative indicator of adsorption capacity, and $1 / n$ indicates the favorable adsorption , $K_{f}$ and $n$ were calculated from the slope and intercept of the plot log qe vs. log Ce. $n$ value indicates the degree of nonlinearity as follows: when $n=1$, adsorption is linear; $n<1$, adsorption is a chemical process; $n>1$, adsorption is a physical process (Kumar, 2014). According to the Freundlich theory, $n>1$ indicates the favorable adsorption (Hai-Ling et al., 2007). The linear form of the Freundlich isotherm from experimental data is given with the following formulas $\left(R^{2}=0.8368\right)$.

$$
\log q_{e}=-3.5387+3.1845 \log C_{e}
$$

Results from this study showed that the $n$ value (0.314) was less than 1 , which suggests that a chemical rather than a physical adsorption was dominant. The value of $n$ lying confirm the unfavorable conditions for adsorption

It was shown that Freundlich isotherm fits beter most of the adsorption data, since the line corresponding to the model fitting is closer to the experimental points than that form Langmuir isotherm. $R^{2}$ values are higher in the case of Freundlich isotherm.

\subsection{Sorption kinetics}

In order to predict the adsorption behavior, kinetic models were employed to the experimental data. In this study, several kinetic models are applied.

The pseudo-first order equation has the following formulation (Eq 6) (Plazinski et al., 2009):

$$
\ln \left(\mathrm{q}_{\mathrm{e}}-\mathrm{q}_{\mathrm{t}}\right)=\ln \mathrm{q}_{\mathrm{e}}-\mathrm{k}_{1} \mathrm{t}
$$

where $\mathrm{q}_{\mathrm{t}}\left(\mathrm{mg} \mathrm{CIP} / \mathrm{g}\right.$ adsorbent) is the concentration of CIP adsorbed in the solid phase at $\mathrm{t}$ time, $\mathrm{k}_{1}(1 / \mathrm{min})$ is the observed rate constant of the pseudo-first-order model and $t(\mathrm{~min})$ is time. The values of $\mathrm{q}_{\mathrm{e}}$ and $\mathrm{k}_{1}$ parameters are usually determined by applying the commonly accepted linear regression procedure. In the first-order kinetic model, by plotting the values of $\ln \left(q_{e}-q_{t}\right)$ vs. $t$ may give a linear relationship that $k_{1}$ and $q_{e}$ values can be determined from the slope and intercept of the obtained line, respectively (Ghaedi and Kokhdan, 2012).

The most commonly-applied form of the pseudo-second order equation can be written in Eq (7):

$$
\frac{t}{q_{t}}=\frac{1}{k_{2} q_{e}^{2}}+\frac{1}{q_{e}} t
$$

where $\mathrm{k}_{2}$ (g adsorbent/ $\mathrm{mg}$ CIP. $\mathrm{min}$ ) is a constant.

The two most commonly used kinetic models were not able to explain the diffusion mechanism and the rate determining step. This is explain by the intraparticle diffusion model and Body kinetic equations (Kumar, 2014).

Intraparticle diffusion model based on diffusive mass transfer that adsorption rate expressed in terms of the square root of time is given (Eq. 8) (Ghaedi and Kokhdan, 2012). 


$$
\mathrm{q}_{\mathrm{t}}=\mathrm{k}_{\text {diff }} \mathrm{t}^{0.5}+\mathrm{C}
$$

$k_{\text {diff }}\left(\mathrm{mg} \mathrm{g}^{-1} \mathrm{~min}^{-0.5}\right)$ is the intraparticle diffusion rate constant and $\mathrm{C}$ is a constant related to the thickness of the boundary layer, which is in direct ratio to the effect of the boundary layer. The value of $k_{\text {diff }}$ and $C$ were calculated from the slope and intercept of the plot of $\mathrm{q}_{\mathrm{t}} \mathrm{vs}$. $\mathrm{t}^{0.5}$. Generally, the plot of $\mathrm{q}_{\mathrm{t}}$ against $\mathrm{t}^{0.5}$ may show a multilinearity, and this indicated that the adsorption processes contained two or more steps. The adsorption of a solute from solution by porous adsorbents is essentially relevant to three consecutive steps. Steps were the external surface adsorption or the instantaneous adsorption, gradual adsorption stage and the final equilibrium stage. If the line passed through the origin, the intraparticle diffusion would be the sole ratelimiting step. If the line did not pass through the origin, it implied that intraparticle diffusion was not the sole rate control step, and other processes may control the adsorption rate (Zou et al., 2012).

The mass transfer effect on the adsorption kinetics can be analyzed by the Body kinetic equation. Equation was applied identify the slowest step in the adsorption process which is expressed as: (Kumar, 2014; Hai-Ling et al., 2007).

$$
\begin{aligned}
& \ln (1-F)=-R^{e_{t}} \\
& F=\frac{q_{t}}{q_{e}}=1-\frac{6}{\pi^{2}} \exp (-B t)
\end{aligned}
$$

when $\mathrm{F}>0.85, \mathrm{Bt}=-\ln (1-\mathrm{F})-0.4977$

where $F$ is the fractional attainment of equilibrium, $R^{e}$ and $B$ are the mass coefficients $(1 / \mathrm{min})$. The linearity of the plot of $\ln (1-F)$ and $t$ indicates the role of the external mass transfer in the adsorption process. The linearity of the plot of Bt against $t$ would show the role of the intraparticle mass transfer (Hai-Ling et al., 2007). Calculated pseudo-first-order, pseudo-second-order, intraparticle, and Body kinetic parameters and coefficient for adsorption of CIP on Kandira stone are listed in Table 1.

Table 1. Comparison of the kinetic parameters for pseudo-first-order and pseudo-second-order, intraparticle, and Body kinetic models

\begin{tabular}{lccccc}
\hline & \multicolumn{2}{c}{ Adsorption kinetic equation } & \multicolumn{2}{c}{ Mass transfer equation } \\
\hline Parameters & $\begin{array}{c}\text { Intraparticle } \\
\text { diffusion }\end{array}$ & First-order & Second-order & $\begin{array}{c}\text { External mass } \\
\text { transfer }\end{array}$ & $\begin{array}{c}\text { Intraparticle mass } \\
\text { transfer }\end{array}$ \\
\hline Rate & $\mathrm{k}_{\text {diff }=0.1479}$ & $\mathrm{k}_{1}=0.086$ & $\mathrm{k}_{2}=0.049$ & $\mathrm{Re}=0.0825$ & $\mathrm{~B}=0.0649$ \\
constant & $\left(\mathrm{mg} / \mathrm{g} . \mathrm{min}^{0.5}\right)$ & $(1 / \mathrm{min})$ & $\left(\mathrm{g} \mathrm{mg}^{-1} \mathrm{~min}^{-1}\right)$ & $(1 / \mathrm{min})$ & $(1 / \mathrm{min})$ \\
\hline $\mathrm{qe}$ & - & 1.74 & 2.17 & - & - \\
\hline $\mathrm{R}^{2}$ & 0.8717 & 0.1282 & 0.9647 & 0.7242 & 0.8131 \\
\hline
\end{tabular}

Comparison of correlation coefficients values showed that the fit of the experimental data by the pseudosecond-order kinetic model gave higher correlation coefficients. Hence, the adsorption behaviour of CIP onto Kandira stone followed the pseudo-second-order kinetic model, indicating that the adsorption process can be expressed with the chemisorption mechanism. The intraparticle diffusion process is a rate-controlling step because of its larger correlation coefficients. $k_{2}$ value from the present study was compared with other adsorbents in previous studies (Table 2). Kandira stone is effective than many adsorbents.

\subsection{Thermodynamics of CIP Adsorption}

Changes of temperature can affect sorption behavior of CIP on Kandira stone, thus sorption of CIP at 20, 30, $40,50{ }^{\circ} \mathrm{C}$ were investigated. The removal of CIP decreased from $51 \%$ to $45 \%$ on increasing the temperature from 20 to $50{ }^{\circ} \mathrm{C}$ for CIP concentration of $30 \mathrm{mg} \mathrm{l}^{-1}$. CIP removal from aqueous solution is difficult at higher temperatures. For all CIP concentration, the maximum removal of CIP was obtained at $20^{\circ} \mathrm{C}$ (Fig. 2). 
The nature of adsorption was ascertained by the thermodynamic analysis of the process. To discuss about thermodynamic behavior of the adsorption of CIP, thermodynamic parameters were calculated.

The relationship between the CIP distribution coefficient $\left(K_{d}\right)$ and free energy $\left(\Delta G^{\circ} \mathrm{J} / \mathrm{mol}\right.$ ) of adsorption (Eq. 12) is:

$$
\Delta \mathrm{G}^{0}=-\mathrm{RT} \ln \mathrm{K}_{\mathrm{d}}
$$

Table 2. $k_{2}$ value of different adsorbents used for removal of CIP

\begin{tabular}{|c|c|c|}
\hline Adsorbent & $k_{2}\left(g g^{-1} \min ^{-1}\right)$ & Reference \\
\hline kaolinite & $855 \times 10^{-3}$ & (Li et al., 2011) \\
\hline montmorillonite & $\begin{array}{l}133.3 \times 10^{-3} \\
2.33 \times 10^{-3}\end{array}$ & $\begin{array}{l}\text { (Wang et al., 2011; Wu et al., } \\
\text { 2010) }\end{array}$ \\
\hline rectorite & $3.33 \times 10^{-3}$ & (Wang et al., 2011) \\
\hline illite & $5 \times 10^{-3}$ & (Wang et al., 2011) \\
\hline modified coal fly ash & 2.07 & (Zhang et al., 2011) \\
\hline $\begin{array}{l}\text { chemically prepared wet and dry } \\
\text { carbon }\end{array}$ & $0.2 \times 10^{-3}$ and $0.18 \times 10^{-3}$ & (El-Shafey et al., 2012) \\
\hline birnessite & $322 \times 10^{-3}$ & (Jiang et al., 2013) \\
\hline $\begin{array}{l}\text { molecularly imprinted polymer and } \\
\text { non-imprinted polymer }\end{array}$ & 1.381 and 0.472 & (Zhang et al., 2012) \\
\hline bentonite & $7.33 \times 10^{-3}$ & \\
\hline zeolite & $7.70 \times 10^{-3}$ & (Genç and Doğan, 2015) \\
\hline pumice & $30.76 \times 10^{-3}$ & \\
\hline Kandira stone & $49 \times 10^{-3}$ & This study \\
\hline
\end{tabular}

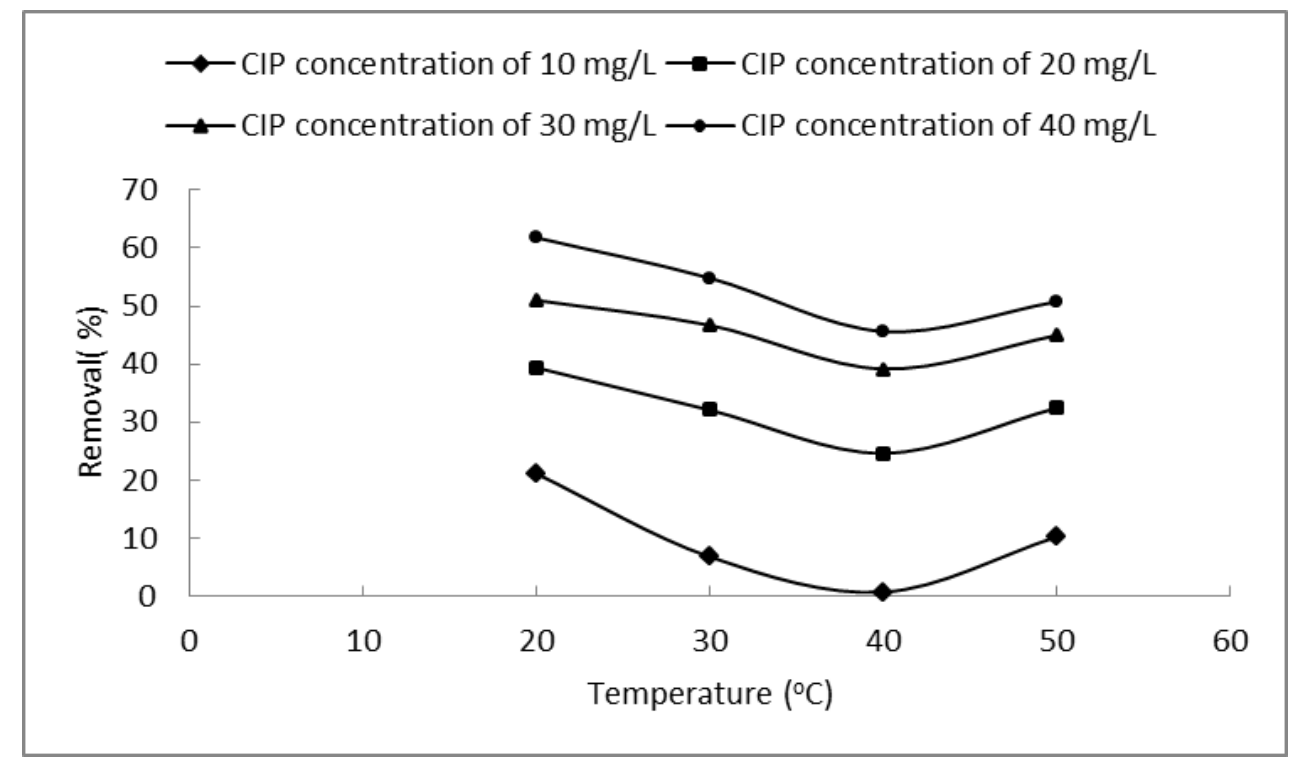

Figure 2. Effect of temperature on the adsorption of CIP

where $\Delta \mathrm{G}^{\circ}$ is the standard free energy change, $\mathrm{R}\left(8.314 \mathrm{~J} \mathrm{~mol}^{-1}{ }^{\circ} \mathrm{K}^{-1}\right)$ is the gas constant and $\mathrm{T}$ is the reaction temperature ( $\left.{ }^{\circ} \mathrm{K}\right)$. The distribution coefficient for the adsorption process $\left(\mathrm{K}_{\mathrm{d}}\right)$ was calculated with Eq. (13) (Li et al., 2014). 


$$
K_{d}=\frac{q_{e}}{C_{e}}
$$

$\Delta \mathrm{H}^{\circ}\left(\mathrm{J} \mathrm{mol}^{-1}\right)$ and $\Delta \mathrm{S}^{\circ}\left(\mathrm{J} \mathrm{mol}^{-1}{ }^{\circ} \mathrm{K}^{-1}\right)$ according to Eq. (14) are calculated (Hai-Ling et al., 2007).

$$
\ln K_{d}=-\frac{\Delta H^{\circ}}{R T}+\frac{\Delta S^{\circ}}{R}
$$

where $\Delta H^{\circ}$ is the isosteric enthalpy change, $\Delta S^{\circ}$ is the entropy change. Where $\Delta H^{\circ}$ and $\Delta S^{\circ}$ were calculated from the slope and intercept of the linear plot of InK $\mathrm{d}_{d}$ against 1/T (Li et al., 2014). The values of the thermodynamic parameters calculated from experimental data are presented in Table 3.

Table 3. Thermodynamic parameters for the adsorption of CIP on Kandira stone

\begin{tabular}{ccccccc}
\hline & \multicolumn{5}{c}{$\Delta \mathrm{G}^{\circ}\left(\mathrm{J} \mathrm{mol}^{-1}\right)$} \\
\hline $\begin{array}{c}\text { Initial CIP } \\
\text { concentration }\left(\mathrm{mg} \mathrm{l}^{-1}\right)\end{array}$ & $\Delta \mathrm{H}^{\circ}\left(\mathrm{J} \mathrm{mol}^{-1}\right)$ & $\Delta \mathrm{S}^{\circ}\left(\mathrm{J} \mathrm{mol}^{-1} \mathrm{~K}^{-1}\right)$ & $20{ }^{\circ} \mathrm{C}$ & $30{ }^{\circ} \mathrm{C}$ & $40{ }^{\circ} \mathrm{C}$ & $50{ }^{\circ} \mathrm{C}$ \\
\hline 10 & $*$ & $*$ & 10202 & - & - & 15437 \\
\hline 20 & -7643 & -51 & 7092 & 8132 & 9355 & 8628 \\
\hline 30 & -5776.6 & -40.3 & 5954 & 6589 & 7608 & 7215 \\
\hline 40 & -6908.9 & -40.9 & 4880 & 5769 & 6921 & 6591 \\
\hline
\end{tabular}

(*)Because the plot of $\operatorname{lnK}_{d}$ versus 1/T was not linear for initial concentration of $10 \mathrm{mg} / \mathrm{L}$, thus the related thermodynamic parameters such as $\Delta \mathrm{H}^{\circ}$ and $\Delta \mathrm{S}^{\circ}$ are not available.

The negative $\Delta \mathrm{H}^{\circ}$ means a chemical exothermic process and support the chemisorption is the ratedetermining step (Eser et al., 2012). When $\Delta \mathrm{G}^{\circ}$ is positive, the reaction is going to be endothermic to go in a forward direction, but will be spontaneous in going backwards. The magnitude of $\Delta G^{\circ}$ depends on temperature and distribution coefficient of adsorption. $\Delta G^{\circ}$ increased by increasing of temperature and decreased by increasing of initial CIP concreation. Entropy has been defined as the degree of chaos of a system (He et al., 2010). The negative entropy changes suggest that more ordered arrangement of solute molecules is shaped on the surface of the adsorbent, which are indicative of an enthalpy-driven adsorption process (HaiLing et al., 2007). $\Delta S^{\circ}$ values increase with the increase of initial CIP concentration because of the higher CIP concentration augments the randomness at the adsorbent -solution interface.

\section{Conclusions}

Batch adsorption experiments were carried out for the removal of CIP by adsorption from aqueous solution using Kandira stone as adsorbent. The effects of parameters adsorbent dosage, contact time, $\mathrm{pH}$ and temperature on the adsorption were investigated. The following conclusions may be drawn:

CIP removal percentage increased by increasing the amount of Kandira stone until $12 \mathrm{~g} \mathrm{l}^{-1}$ owing to a corresponding increase in the number of active sites, removal of CIP was $68.5 \%$ at $12 \mathrm{~g} \mathrm{I}^{-1}$. The removal percentage do not change significantly at higher value of Kandira stone due to overlapping or aggregation of adsorption sites. The equilibrium adsorption is practically achieved through a time of $30 \mathrm{~min}$, removal of CIP was $63.9 \%$ at $30 \mathrm{~min}$. Due to CIP exist in a cationic form in acidic solution, CIP adsorption was high. The removal percentage significantly decreased at higher $\mathrm{pH}$ values. $\mathrm{At} \mathrm{pH}<6.0$, removal of $\mathrm{CIP}$ increased because of the electrostatic attraction improved due to the opposite charge between CIP and Kandira stone. Kinetic models were used to analyze the experimental data. The kinetic study was performed based on pseudo-firstorder, pseudo-second-order equations, intraparticle diffusion and Body kinetic equations. The data indicate that the adsorption kinetics follow the second-order kinetic models. The results of this study indicate that Kandira stone is efficient adsorbent for the removal CIP, although it shows a lower adsorption capacity than 
those observed on other minerals. $\mathrm{k}_{2}$ (g adsorbent/mg CIP $\mathrm{min}$ ) value for Kandira stone was calculated as $49 \times 10^{-3}$. Also, the intraparticle diffusion process is determined as a rate controlling step because of its larger correlation coefficients. The equilibrium data have been analyzed using Freundlich and Langmuir adsorption isotherms. The sorption data follows Freundlich isotherm. The Freundlich type adsorption isotherm is an indicator of surface heterogeneity. Results from this study showed that the $n$ value $(0.314)$ was less than 1 , which suggests that a chemical rather than a physical adsorption was dominant. The removal of CIP decreases with increase in temperature, the maximum removal of CIP was obtained at $20^{\circ} \mathrm{C}$. Thermodynamic of $\mathrm{CIP}$ adsorption shows that adsorption is the exothermic adsorption. $\Delta \mathrm{S}^{\circ}$ values increase with the increase of initial CIP concentration because of the higher CIP concentration augments the randomness at the adsorbent solution interface.

\section{References}

Arman H., Ramazanoglu S. and Akinci A. (2007), Mechanical and physical properties of the Kandira stone, Kandira, Turkey, Bull Eng Geol Environ, 66, 331-333.

Bajpai S.K., Bajpai M. and Rai N. (2012), Sorptive removal of ciprofloxacin hydrochloride from simulated wastewater using sawdust: Kinetic study and effect of pH, Water SA, 38(5), 673-682.

Bhandari A., Close L.I., Kim W., Hunter R.P., Koch D.E. and Suramalli R.Y. (2008), Occurence of ciprofloxacin, sulfamethoxazole, and azithromycin in municipal wastewater treatment plants, Practice Periodical of Hazardous, Toxic, and Radiaoactive Waste Management, 12(4), 275-281.

Carabineiro S.A.C., Thavorn-Amornsri T., Pereira M.F.R., Serp P. and Figueiredo J.L. (2012), Comparison between activated carbon, carbon xerogeland carbon nanotubes for the adsorption of the antibiotic ciprofloxacin, Catalysis Today, 186, 29-34.

Carmosini N. and Lee L.S. (2009), Ciprofloxacin sorption by dissolved organic carbon from reference and bio-waste materials, Chemosphere, 77(6), 813-820.

Carrasquillo A.J., Bruland G.L., Mackay A.A. and Vasudevan D. (2008), Sorption of ciprofloxacin and oxytetracycline zwitterions to soils and soil materials: influence of compound structure, Environmental Science and Technology, 42, 7634-7642.

Conkle J.L., Lattao C., White J.R. and Cook R.L.(2010) Competitive sorption and desorption behavior for three fluoroquinolone antibiotics in awastewater treatment wetland soil, Chemosphere, 80(11), 1353-1359.

Daughton C.G. and Ternes T.A. (1999), Pharmaceuticals and personal care products in the environment: agent of subtle change?, Environ. Health Perspect, 107, 907-938.

El-Shafey E.S.I., Al-Lawati H. and Al-Sumri A.S. (2012), Ciprofloxacin adsorption from aqueous solution onto chemically prepared carbon from date palm leaflets, Journal of Environmental Sciences, 24(9), 1579-1586.

Eser A., Tirtom V.N., Aydemir T., Becerik S. and Dinçer A. (2012), Removal of nickel (II) ions by histidine modified chitosan beads, Chemical Engineering Journal, 210, 590-596.

Genç N. and Dogan E.C. (2015), Adsorption Kinetics of the Antibiotic Ciprofloxacin on Bentonite, Activated Carbon, Zeolite and Pumice, Desalination and Water Treatment, 53,785-793.

Ghaedi M. and Kokhdan S.N. (2012), Oxidized multiwalled carbon nanotubes for the removal of methyl red (MR): kinetics and equilibrium study, Desalination and Water Treatment, 49, 317-325.

Golet E.M., Strehler A., Alder A.C. and Giger W. (2002), Determination of fluoroquinolone antibacterial agents in sewage sludge and sludge-treated soil using accelerated solvent extraction followed by solid-phase extraction, Analytical Chemistry, 74(21), 5455-5462.

Gu C. and Karthikeyan K.G. (2005), Sorption of the antimicrobial ciprofloxacin to aluminum and iron hydrous oxides, Environmental Science and Technology, 39, 9166-9173. 
Hai-Ling W., Zheng-Hao F., Jin-long C., Quan-Xing Z. and Yan-long X.U. (2007), Adsorption thermodynamics and kinetic investigation of aromatic amphoteric compounds onto different polymeric adsorbents, Journal of Environmental Sciences, 19, 1298-1304.

He J., Hong S., Zhang L., Gan F. and Ho Y.S. (2010), Equilibrium and thermodynamic parameters of adsorption of methylene blue onto rectorite, Fresenius Environmental Bulletin, 19-No 11a.

Ibezim E.C., Ofoefule S.I., Ejeahalaka C.N.E. and Orisakwe O.E.(1999), In vitro adsorption of ciprofloxacin on activated charcoal and talc, American Journal of Terapeutics, 6(4), 199-201.

Jiang W.T., Chang P.H., Wang Y.S., Tsai Y., Jean J.S., Li Z. and Krukowski K.(2013), Removal of ciprofloxacin from water by birnessite, Journal of Hazardous Materials, 250-251, 362-369.

Kumar P.(2014), Adsorption of Lead (II) lons from Simulated Wastewater Using Natural Waste: A Kinetic, Thermodynamic and Equilibrium Study, Environmental Progress\&Sustainable Energy, 33, 55-64.

Li H., Zhang D., Han X., Xing B. (2014), Adsorption of antibiotic ciprofloxacin on carbon nanotubes: $\mathrm{pH}$ dependence and thermodynamics, Chemosphere, 95, 150-155.

Li Z., Hong H., Liao L., Ackley C.J., Schulz L.A., MacDonald R.A., Mihelich A.L. and Emard S.M.(2011), A mechanistic study of ciprofloxacin removal by kaolinite, Colloids and Surfaces B: Biointerfaces, 88, 339-344.

Moradi O., Fakhri A.and Adami S.(2013), Isotherm, thermodynamic, kinetics, and adsorption mechanism studies of Ethidium bromide by single-walled carbon nanotube and carboxylate group functionalized single-walled carbon nanotube, Journal of Colloid and Interface Science, 395, 224-229.

Plazinski W., Rudzinski W. and Plazinska A.(2009), Theoretical models of sorption kinetics including a surface reaction mechanism: A review, Advances in Colloid and Interface Science, 152, 2-13.

Qinfeng W., Zhaohui L. and Hanlie H. (2012), Influenceof types and charges of exchangeable cations on ciprofloxacin sorption by montmorillonite, Journal of Wuhan University of Technology-Materials Science, 27(3), 516-522.

Rakshit S., Sarkar D., Elzinga E.J., Punamiya P. and Datta R.(2013), Mechanisms of ciprofloxacin removal by nano-sized magnetite, Journal of Hazardous Materials, 246-247, 221-226.

Reynaud F., Tsapis N., Deyme M., Vasconcelos T.G., Gueutin C., Guterres S.S., Pohlmann A.R. and Fattal E. (2011), Spraydried chitosan-metal microparticles for ciprofloxacin adsorption: Kinetic and equilibrium studies, Soft Matter, 7(16), 7304-7312.

Shi S., Fan Y.W. and Huang Y.M.(2013), Facile low temperature hydrothermal synthesis of magnetic mesoporous carbon nanocomposite for adsorption removal of ciprofloxacin antibiotics, Industrial \& Engineering Chemistry Research, 52(7), 2604-2612.

Vasudevan D., Bruland G.L., Torrance B.S., Upchurch V.G. and MacKay A.A. (2009), pH-dependent ciprofloxacin sorption to soil: Interaction mechanisms and soil factors influencing sorption, Geoderma, 151, 68-76.

Wang C.J., Li Z. and Jiang W.T. (2011), Adsorption of ciprofloxacin on 2:1 dioctahedral clay minerals, Applied Clay Science, 53, 723-728.

Wu C., Spongberg A.L. and Witter J.D. (2009), Sorptionand biodegradation of selected antibiotics in biosolids, Journal of Environmental Science and Health Part A, 44, 454-461.

Wu Q., Li Z., Hong H., Yin K. and Tie L.(2010), Adsorption and intercalation of ciprofloxacin on montmoriionite, Applied Clay Science, 50, 204-211.

Zhang X., Gao X., Huo P and, Yan Y. (2012), Selective adsorption of micro ciprofloxacin by molecularly imprinted functionalized polymers appended onto ZnS, Environmental Technology, 33(17), 2019-2025.

Zhang C.L., Qiao G.L., Zhao F. and Wang Y. (2011), Thermodynamic and kinetic parameters of ciprofloxacin adsorption onto modified coal fly ash from aqueous solution, Journal of Molecular Liquids, 163, 53-56.

Zou W., Bai H. and Gao S. (2012), Competitive adsorption of neutral red and $\mathrm{Cu}^{2+}$ onto pyrolytic char: Isotherm and kinetic study, Journal of Chemical \& Engineering, 57, 2792-2801. 